\title{
Troponin in diabetic patients with and without chronic coronary artery disease
}

\author{
Carlos Alexandre Wainrober Segre, Whady Hueb*, Rosa Maria Rahmi Garcia, Paulo Cury Rezende, \\ Desiderio Favarato, Celia Maria Cassaro Strunz, Marília da Costa Oliveira Sprandel, Alessandra Roggério, \\ Ana Luiza de Oliveira Carvalho, Raul Cavalcante Maranhão, José Antonio Franchini Ramires and Roberto Kalil Filho
}

\begin{abstract}
Background: Cardiac-specific troponin detected with the new high-sensitivity assays can be chronically elevated in response to cardiovascular comorbidities and confer important prognostic information, in the absence of unstable coronary syndromes. Both diabetes mellitus and coronary artery disease are known predictors of troponin elevation. It is not known whether diabetic patients with coronary artery disease have different levels of troponin compared with diabetic patients with normal coronary arteries. To investigate this question, we determined the concentrations of a level 1 troponin assay in two groups of diabetic patients: those with multivessel coronary artery disease and those with angiographically normal coronary arteries.
\end{abstract}

Methods: We studied 95 diabetic patients and compared troponin in serum samples from 50 patients with coronary artery disease (mean age $=63.7,58 \%$ male) with 45 controls with angiographically normal coronary arteries. Brain natriuretic peptide and the oxidative stress biomarkers myeloperoxidase, nitrotyrosine and oxidized LDL were also determined.

Results: Diabetic patients with coronary artery disease had higher levels of troponin than did controls (median values, $12.0 \mathrm{pg} / \mathrm{mL}$ (95 \% Cl:10-16) vs $7.0 \mathrm{pg} / \mathrm{mL}$ (95\% Cl: 5.9-8.5), respectively; $p=0.0001$ ). The area under the ROC curve for the diagnosis of CAD was 0.712 with a sensitivity of $70 \%$ and a specificity of $66 \%$. Plasma BNP levels and oxidative stress variables (myeloperoxidase, nitrotyrosine, and oxidized LDL) were not different between the two groups. In a multivariate analysis, gender $(p=0.04)$, serum glucose $(0.03)$ and Troponin I $(p=0.01)$ had independent statistical significance.

Conclusion: Troponin elevation is related to the presence of chronic coronary artery disease in diabetic patients with multiple associated cardiovascular risk factors. Troponin may serve as a biomarker in this high-risk population.

Trial registration: http://www.controlled-trials.com Registration number:ISRCTN26970041

Keywords: Biological markers, Troponin, Diabetes mellitus, Coronary artery disease

\section{Background}

Cardiac-specific troponins (cTn) have received international endorsement as the standard biomarkers for detection of myocardial injury [1]. To enhance diagnostic sensitivity, new methods have been developed recently that can detect very low levels of troponin in the blood and have resulted in improved diagnostic accuracy [2], but have, on the other hand, led to loss of specificity:

\footnotetext{
* Correspondence: whady.hueb@incor.usp.br
Department of Clinical Cardiology, Heart Institute (InCor) University of São
Paulo, Av. Dr. Eneas de Carvalho Aguiar 44, AB, BL I, Sala 114, Cerqueira

* Correspondence: whady.hueb@incor.usp.br
Department of Clinical Cardiology, Heart Institute (InCor) University of São
Paulo, Av. Dr. Eneas de Carvalho Aguiar 44, AB, BL I, Sala 114, Cerqueira

* Correspondence: whady.hueb@incor.usp.br
Department of Clinical Cardiology, Heart Institute (InCor) University of São
Paulo, Av. Dr. Eneas de Carvalho Aguiar 44, AB, BL I, Sala 114, Cerqueira César, Sao Paulo, SP 05403-000, Brazil
}

cTn has become detectable in subjects without acute myocardial injury $[3,4]$. Besides having become detectable in subjects without acute heart disease, detectable cTn is associated with cardiovascular comorbidities and higher mortality in the general population [5-8] and in many disease conditions $[9,10]$.

Assuming that diabetes is a microvascular disease and therefore contributes to chronic myocite injury [11], several mechanisms may contribute to the increased risk of coronary artery disease (CAD) development [12-14], such as metabolic factors (advanced glycation end products and lipoprotein abnormalities) [15], coagulation 
abnormalities [16], endothelial dysfunction [17] and higher levels of oxidative stress [18]. Consistent with these functional alterations, the presence of type 2 diabetes mellitus was already a known predictor of elevated cardiac troponin in the general population with the older assays [19]. With the new assays, detection in the general population has become more common: circulating high sensitivity troponin $\mathrm{T}$ was measurable in $90 \%$ of otherwise healthy diabetic patients [20]. These elevations are related to cardiovascular disease and cardiovascular death in diabetic compared to nondiabetic patients [21].

In patients with chronic CAD, concentrations of high sensitivity troponin $\mathrm{T}$ are higher than that in healthy controls $[22,23]$ and correlate with the incidence of cardiovascular death or heart failure $[23,24]$ and total mortality [25]. The extent of CAD measured by the coronary plaque burden on cardiac computed tomographic angiography also correlates with high sensitivity troponin $\mathrm{T}$ [26].

Therefore, both diabetes mellitus and chronic CAD are known predictors of elevation of cTn $[6,23]$. It is not known whether diabetic patients with CAD have different levels of cTn compared with diabetic patients with normal coronary arteries. To investigate this question, we determined the levels of cTn in two groups of diabetic patients: patients with multivessel CAD and those with angiographically normal coronary arteries.

\section{Methods}

\section{Study subjects}

The study included patients with type 2 diabetes mellitus with angiographically documented proximal multivessel coronary stenosis of $>70 \%$, these patients had normal ventricular function and received optimal medical treatment without coronary revascularization. This group of patients with multivessel CAD was compared to patients with type 2 diabetes mellitus and angiographically normal coronary arteries identified by angiogram or coronary tomography, also with normal ventricular function.

The following were considered as exclusion criteria: smoking, left ventricular dysfunction, atrial fibrillation, uncontrolled hypertension (systolic blood pressure greater than $180 \mathrm{~mm} \mathrm{Hg}$ and/or diastolic blood pressure greater than $100 \mathrm{~mm} \mathrm{hg})$, chronic kidney disease $(\mathrm{GFR}=45$ $59 \mathrm{~mL} / \mathrm{min}$ or less), hepatic impairment, hypothyroidism, recent surgery, and degenerative musculoskeletal disease.

The study conformed to the guidelines set out in the Declaration of Helsinki and was approved by the Ethics Committee of the University of São Paulo Medical School. All participants gave written informed consent for participation in the study.

Patients were instructed to interrupt statin use 45 days before blood collection. Blood samples were collected after a 12-h fast. After centrifugation, plasma was aliquoted and stored at $-70{ }^{\circ} \mathrm{C}$ until analysis.

\section{Laboratory analysis}

Glucose, glycated hemoglobin (HbA1c), total cholesterol, and triglycerides were determined from serum samples after a 12-h fast, by using specific kits in the automated equipment Dimension RxL (Siemens Healthcare, Newark, USA). HDL-cholesterol was measured by a homogeneous enzymatic colorimetric method specific for Dimension RxL. LDL-cholesterol was estimated using the Friedewald formula.

\section{Cardiac troponin I}

Cardiac troponin-I was determined using the ADVIA Centaur $^{\circ}$ TnI-Ultra kit (Siemens Healthcare Diagnostics, NY, USA) in the automated equipment of the same manufacturer. The test is an immunoassay that uses a direct chemiluminescence technology and constant amounts of two monoclonal antibodies. An increased TnI concentration is defined as a value exceeding the 99th percentile of a normal reference population. According to the manufacturers, the detection limit is $0.006 \mathrm{ng} / \mathrm{mL}$, the population reference value at the 99th percentile is $<0.04 \mathrm{ng} / \mathrm{mL}$, and the coefficient of variation is $<10 \%$ at this 99 th percentile.

Siemens Centaur ultra is not considered a highsensitivity assay, instead, it is designated as a contemporary or level 1 assay. The new troponin assays are defined by their ability to detect troponin above the limit of detection in normal individuals and classified according to the percentage of normal individuals detected in four categories: level 1 corresponds to $<50 \%$ of measurable normal values, level 2: 50-75 \%, level 3: 75-95 \%, and level 4: $\geq 95 \%$. Only levels two to four are considered highsensitivity assays [27]. We have used the designation level 1 assay or the general designation: cardiac troponin.

\section{Brain natriuretic peptide and oxidative and myocardial stress biomarkers}

The oxidative stress biomarkers myeloperoxidase and nitrotyrosine were determined using solid-phase enzyme linked immunosorbent assays (Hycult, Uden, The Netherlands). Oxidized LDL was determined using a competitive enzyme linked immunosorbent assay (Mercodia, Uppsala, Sweden).

Brain natriuretic peptide (BNP) concentrations were determined through chemiluminescence immunoassay (Siemens Healthcare Diagnostics, NY, USA).

\section{Statistical analysis}

Data were analyzed using MedCalc (version 12). Median and interquartile ranges were used to show skewed troponin values. The categorical variables are presented as absolute and relative (\%) values. A two-tailed $p$ value $<0.05$ was considered significant. Baseline characteristics of patients were examined in coronary artery disease and control groups. The Student's $t$ test was used for continuous variables and the chi-squared 
test or Fisher's exact test for categorical variables. The Mann-Whitney test was used for nonparametrical variables. Multivariate analysis was performed using logistic regression, the model being composed of variables with $p<0.20$ in the univariate analysis.

\section{Results}

Between January 2011 and March 2012, 95 diabetic patients were included in this study. Fifty patients had chronic coronary artery disease while the remaining 45 patients, the control group, had angiographically normal arteries. The clinical and laboratory characteristics of study participants are shown in Table 1 . There were no significant differences among the two groups. Patients with CAD had higher concentrations of total cholesterol and LDL cholesterol.

Plasma BNP concentrations and oxidative stress variables (myeloperoxidase, nitrotyrosine, and oxidized LDL) are shown in Table 2. Concentrations were not significantly different between the two groups.

As shown in Fig. 1, diabetic patients with CAD had higher levels of troponin than did controls: median values, $12.0 \mathrm{pg} / \mathrm{mL}(95 \%$ CI:10-16 $\mathrm{pg} / \mathrm{mL})$ vs $7.0 \mathrm{pg} / \mathrm{mL}$ (95\% CI: 5.9-8.5 pg/mL), respectively; $\mathrm{p}=0.0001$. The area under the ROC curve for the diagnosis of CAD, shown in Fig. 2 was 0.712 with a sensitivity of $70 \%$ and a specificity of $66 \%$. In the multivariate analysis performed and shown in Table 3, gender $(p=0.04)$, Troponin I $(\mathrm{p}=0.01)$, and serum glucose with a negative correlation coefficient $(\mathrm{p}=0.03)$ had independent statistical significance.

Table 1 Patients characteristics

\begin{tabular}{llll}
\hline Characteristic $^{\mathrm{a}}$ & CAD $(\mathrm{n}=50)$ & Controls $(\mathrm{n}=45)$ & $P$ Values \\
\hline Age, mean $\pm \mathrm{SD}, \mathrm{y}$ & $63.3 \pm 8.3$ & $61.4 \pm 9.4$ & 0.34 \\
Female $\mathrm{n}(\%)$ & $20(42)$ & $26(60,5)$ & 0.07 \\
Hypertension $\mathrm{n}(\%)$ & $40(83)$ & $36(84)$ & 0.42 \\
Waist, mean $\pm \mathrm{SD}(\mathrm{cm})$ & $103 \pm 13$ & $108 \pm 17$ & 0.09 \\
BMl, mean $\pm \mathrm{SD}, \mathrm{Kg} / \mathrm{m}^{2}$ & $30.6 \pm 6.3$ & $32.4 \pm 6.7$ & 0.22 \\
Total Cholesterol (mg/ dL) & $216 \pm 45$ & $193 \pm 33$ & 0.01 \\
LDL Cholesterol $(\mathrm{mg} / \mathrm{dL})$ & $142 \pm 41$ & $124 \pm 31$ & 0.03 \\
HDL Cholesterol $(\mathrm{mg} / \mathrm{dL})$ & $37 \pm 8$ & $39 \pm 8$ & 0.47 \\
Triglycerides (mg/dL) & $173 \pm 75$ & $163 \pm 70$ & 0.55 \\
Serum Glucose $(\mathrm{mg} / \mathrm{dL})$ & $124 \pm 37$ & $134 \pm 32$ & 0.18 \\
Hemoglobin A1C(mg/dL) & $7.2 \pm 1.8$ & $7.3 \pm 1.6$ & 0.61 \\
Insulin use $n(\%)$ & $12(25)$ & $11(26)$ & 0.43 \\
Duration of diabetes, y & $9.9 \pm 9.7$ & $7.07 \pm 6.9$ & 0.16 \\
\hline
\end{tabular}

${ }^{\mathrm{a} C A D}$ indicates coronary artery disease, BMI indicates body mass index, LDL cholesterol indicates low density lipoprotein, HDL cholesterol indicates High density lipoprotein, Hemoglobin A1C indicates glycated hemoglobin
Table 2 BNP and oxidative stress variables

\begin{tabular}{llll}
\hline Variable & CAD & Controls & $P$ Values \\
\hline $\begin{array}{l}\text { BNP }(n=78), \\
\text { median values }(n), \mathrm{pg} / \mathrm{mL}\end{array}$ & $37,0(34)$ & $28.5(44)$ & 0.08 \\
$\begin{array}{l}\text { Nitrotyrosine }(\mathrm{n}=68), \\
\text { median values }(\mathrm{n}), \mathrm{nm} / \mathrm{mL}\end{array}$ & $27.9(36)$ & $28.7(32)$ & 0.77 \\
$\begin{array}{l}\text { Myeloperoxidase }(\mathrm{n}=68), \\
\text { median values, } \mathrm{ng} / \mathrm{mL}\end{array}$ & $33.0(37)$ & $27.0(31)$ & 0.96 \\
$\begin{array}{l}\text { Oxidized } \mathrm{LDL}(\mathrm{n}=71), \\
\text { median values }(\mathrm{n}), \mathrm{mU} / \mathrm{L}\end{array}$ & $14.8(35)$ & $11.2(36)$ & 0.09 \\
\hline
\end{tabular}

$B N P$ indicates B-type natriuretic peptide, Oxidized $L D L$ indicates oxidized

low-density lipoprotein

\section{Discussion}

In the present study, we evaluated cTn levels in 95 diabetic patients with preserved ventricular function, in the absence of an acute coronary syndrome. We found that concentrations of cTn were significantly higher $(\mathrm{p}=$ 0.0001) in diabetic patients with stable coronary artery disease. This finding is consistent with that in other studies that have also shown elevation of cTn in stable coronary artery disease patients [22, 23, 26, 28], but these studies were not specifically designed to test this hypothesis in diabetic patients. The specific contribution of our study is to confirm the association of cTn elevation with $\mathrm{CAD}$ in diabetic patients with multiple associated cardiovascular risk factors, demonstrating that $\mathrm{cTn}$ is also a useful biomarker in patients with diabetes mellitus. This conclusion is not straightforward, because diabetes mellitus "per se" is associated with an elevation in cTn concentrations [20, 21]. Although a study that investigated high sensitivity Troponin $\mathrm{T}$ concentrations in diabetic patients has shown an association with age, gender, and renal function but not with the presence of CAD [20]. In another study that used high sensitivity Troponin I, and a larger

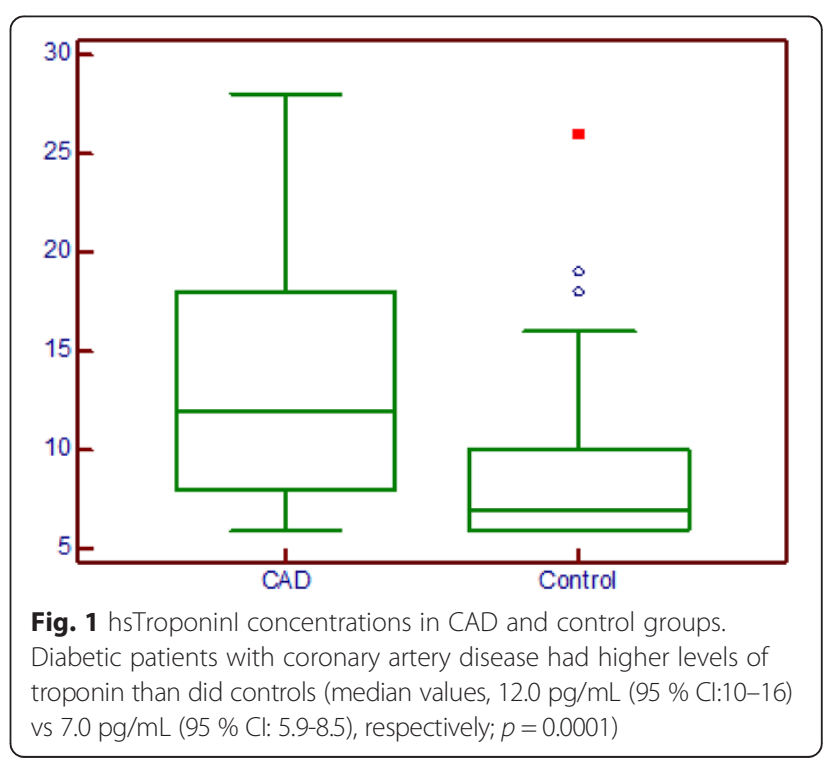




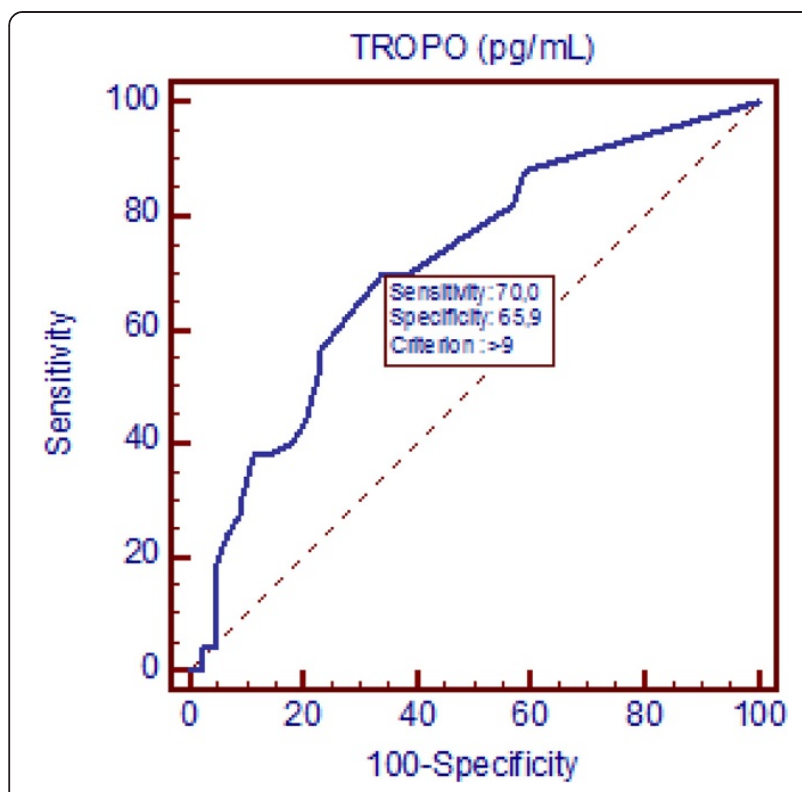

Fig. 2 ROC curve for the diagnosis of CAD. The area under the ROC curve for the diagnosis of CAD was 0.712 with a sensitivity of $70 \%$ and a specificity of $66 \%$

number of patients with longer follow-up, troponin I elevation was a predictor of CAD [29]. These two studies did not include multivessel coronary artery disease patients. It is possible that troponin release is related to more diffuse coronary disease, which is a prognostic factor in coronary artery disease [30], and is considered more common among diabetic patients with triple vessel disease [31], which is the group of patients included in our study sample.

Meta-analyses suggest that a previous generation of cardiac troponins $\mathrm{I}$ and $\mathrm{T}$ had comparable diagnostic and prognostic performance in most clinical settings [32]. The new assays have detected different biological characteristics in high-sensitivity troponin $\mathrm{I}$ and $\mathrm{T}$ that may be clinically relevant. In a study that compared both biomarkers in a large number of patients, the correlation between the concentrations of the two biomarkers was only of moderate strength. Elevated concentrations of troponin I, but not troponin T, were significantly and independently associated with both prior and the incidence of subsequent acute myocardial infarction [24]. In our study, we have also used troponin I, which again, has shown a good correlation with the presence of CAD. Studies with a larger number of patients comparing the two types of troponin would be necessary to determine which one correlates better with the presence of CAD. Until now, evidence points to the use of troponin I to this purpose.

The reason for the discrepancy between the concentrations of the two types of troponin is not known, and the mechanism that causes troponin release in patients with coronary artery disease is still under investigation. Many hypotheses have been proposed, including transient, clinically silent ischemic episodes and small vessel occlusion, inflammatory processes, cardiomyocyte apoptosis [33], leakage of a cytoplasmatic pool of troponins [34], and plaque microembolization, because the concentrations of high-sensitivity troponin $\mathrm{T}$ are related to noncalcified plaque burden and vascular remodeling [28]. In our study, cTn concentrations in diabetic patients without CAD were low and close to the limit of detection of the method used. This result suggests that troponin release is related to the presence of coronary atherosclerosis and not to any other kind of damage to the heart caused by diabetes mellitus.

In the sample studied, total cholesterol and LDL cholesterol concentrations were higher among CAD patients, confirming a finding that is well established among different populations [35]. One unanticipated finding is that serum glucose and hemoglobin $\mathrm{A} 1 \mathrm{C}$ concentrations were not different between CAD patients and the control group. However, in the multivariate analysis, serum glucose (with a negative correlation coefficient) was related to

Table 3 Multiple regression

\begin{tabular}{|c|c|c|c|c|c|}
\hline Independent variables & Coefficient & Std. Error & $r_{\text {partial }}$ & $\mathrm{t}$ & $P$ \\
\hline (Constant) & -0.04849 & & & & \\
\hline Waist & -0.002267 & 0.003964 & -0.07906 & -0.572 & 0.5699 \\
\hline Gender & 0.2735 & 0.1304 & 0.2794 & 2.098 & 0.0408 \\
\hline TC & 0.004189 & 0.002269 & 0.2480 & 1.846 & 0.0706 \\
\hline LDL & -0.00007268 & 0.002797 & -0.003604 & -0.0260 & 0.9794 \\
\hline Glucose & -0.003659 & 0.001730 & -0.2815 & -2.115 & 0.0392 \\
\hline Duration_of_diabetes & 0.01060 & 0.008039 & 0.1799 & 1.319 & 0.1930 \\
\hline BNP & -0.001938 & 0.002445 & -0.1092 & -0.792 & 0.4317 \\
\hline Ox_LDL & -0.0003638 & 0.01383 & -0.003649 & -0.0263 & 0.9791 \\
\hline Tropo & 0.02919 & 0.01135 & 0.3359 & 2.572 & 0.0130 \\
\hline
\end{tabular}


CAD in diabetic patients. Hyperglycemia is a risk factor for CAD in epidemiological studies [36]. The unexpected finding of a negative correlation between serum glucose and CAD is probably related to a bias in the study sample, in which the control group had slightly worse, but not statistically significant, glycemic control. Another factor that could explain the lack of difference in glycemic control among $\mathrm{CAD}$ and controls is that macrovascular complications do not correlate linearly with HbA1c [37] and the presence of prior vascular disease is one of the predictors of poor cardiovascular outcomes after treatment intensification for insufficient glycemic control [38]. As regards gender, male sex is a well-known risk factor for CAD [39] and also correlated with $\mathrm{CAD}$, in the multivariate analysis, in this study.

\section{Limitations}

The troponin kit used in this study is not among the most sensitive tests available [27], nevertheless, the sensitivity was high enough to show a significant difference between the two groups studied.

Other limitations of this study deserve comment. First, the number of patients is relatively small, and the findings need to be confirmed in larger studies. Second, this is a case-control study that cannot provide information on prognostic implications of subjects with elevated high-sensitivity troponin.

\section{Conclusion}

Troponin elevation is related to the presence of chronic coronary artery disease in diabetic patients with multiple associated cardiovascular risk factors. Troponin may serve as a biomarker in this high-risk population.

\section{Abbreviations \\ CTn: Cardiac troponin.; CAD: Coronary artery disease; BMI: Body mass index; LDL cholesterol: Low-density lipoprotein; HDL cholesterol: High-density lipoprotein; TG: Triglycerides; Hemoglobin A1C: Glycated hemoglobin; BNP: B-type natriuretic peptide; Oxidized LDL: Oxidized low-density lipoprotein.; $P$ value: Calculated probability of statistical significance; N: Number of patients; GFR: Glomerular Filtration Rate.}

\section{Competing interests}

The authors declare that they have no competing interests.

\section{Authors' contributions}

CAWS conceived and designed the research, analyzed the data, drafted the manuscript, and agrees to be accountable for all aspects of the work in ensuring that questions related to the accuracy or integrity of any part of the work are appropriately investigated and resolved. WH conceived and designed the research, made critical revision of the manuscript for important intellectual content, and gave final approval of the manuscript submitted. RMRG substantial contributions to the conception or design of the work. PCR substantial contributions to the conception or design of the work. DF data acquisition, statistical analysis. CMCS acquisition, analysis, or interpretation of data for the work. MCOS acquisition, analysis, or interpretation of data for the work. AR acquisition, laboratorial analysis and interpretation of data. ALOC acquisition, analysis, or interpretation of data for the work. RCM Drafting the work or revising it critically for important intellectual content, and final approval of the version to be published. JR Final approval of the version to be published.
RKF Final approval of the version to be published. All authors read and approved the final manuscript.

\section{Acknowledgement}

Medical writing support was provided by Ann Conti Morcos of MorcosMedia during the preparation of this paper.

\section{Financial support}

Financial support for the present study was provided in part by a research grant from the Zerbini Foundation, and supported by the FAPESP (2010/ 52025-9).

Received: 24 February 2015 Accepted: 1 June 2015

Published online: 21 July 2015

\section{References}

1. Apple FS, Collinson PO. IFCC Task Force on Clinical Applications of Cardiac Biomarkers. Analytical characteristics of high-sensitivity cardiac troponin assays Clin Chem. 2012;58(1):54-61.

2. Reichlin T, Hochholzer W, Bassetti S, Steuer S, Stelzig C, Hartwiger S, et al. Early diagnosis of myocardial infarction with sensitive cardiac troponin assays. N Engl J Med. 2009;361(9):858-67.

3. Twerenbold R, Jaffe A, Reichlin T, Reiter M, Mueller C. High-sensitive troponin T measurements: what do we gain and what are the challenges? Eur Heart J. 2012;33(5):579-86.

4. Sethi A, Bajaj A, Malhotra G, Arora RR, Khosia S. Diagnostic accuracy of sensitive or high-sensitive troponin on presentation for myocardial infarction: a meta-analysis and systematic review. Vasc Health Risk Manag. 2014;10:435-50.

5. de Lemos JA, Drazner MH, Omland T, Ayers CR, Khera A, et al. Association of troponin $\mathrm{T}$ detected with a highly sensitive assay and cardiac structure and mortality risk in the general population. JAMA. 2010;304(22):2503-12.

6. Eggers KM, Al-Shakarchi J, Berglund L, Lindahl B, Siegbahn A, Wallentin L, et al. High-sensitive cardiac troponin $T$ and its relations to cardiovascular risk factors, morbidity, and mortality in elderly men. Am Heart J. 2013;166(3):541-8.

7. de Filippi CR, de Lemos JA, Christenson RH, Christenson RH, Gottdiener JS, Kip WJ, et al. Association of serial measures of cardiac troponin T using a sensitive assay with incident heart failure and cardiovascular mortality in older adults. JAMA. 2010;304(22):2494-502.

8. Saunders JT, Nambi V, de Lemos JA, Chambless LE, Virani SS, Boerwinkle E, et al. Cardiac troponin T measured by a highly sensitive assay predicts coronary heart disease, heart failure, and mortality in the Atherosclerosis Risk in Communities Study. Circulation. 2011;123(13):1367-76.

9. Omland T. New features of troponin testing in different clinical settings. J Intern Med. 2010;268(3):207-17.

10. Apple FS. High-sensitivity cardiac troponin for screening large populations of healthypeople: is there risk? Clin Chem. 2011;57(4):537-9.

11. Laakso M. Heart in diabetes: a microvascular disease. Diabetes Care. 2011;34 Suppl 2:S145-9.

12. Grundy SM, Benjamin IJ, Burke GL, Chait A, Eckel RH, Howard BV, et al. Diabetes and cardiovascular disease: a statement for healthcare professionals from the American Heart Association. Circulation. 1999;100(10):1134-46.

13. Kannel WB, McGee DL. Diabetes and cardiovascular disease. The Framingham study JAMA. 1979;241(19):2035-8.

14. Zimmet P, Alberti KG, Shaw J. Global and societal implications of the diabetes epidemic. Nature. 2001;414(6865):782-7.

15. Eckel RH, Wassef M, Chait A, Sobel B, Barrett E, King G, et al. Prevention Conference VI: Diabetes and Cardiovascular Disease: Writing Group II: pathogenesis of atherosclerosis in diabetes. Circulation. 2002;105(18):e138-43.

16. Vazzana N, Ranalli P, Cuccurullo C, Davi G. Diabetes mellitus and thrombosis. Thromb Res. 2012;129(3):371-7.

17. Makimattila S, Virkamäki A, Groop PH, Cockcroft J, Utriainenb T, Fagerudd J, et al. Chronic hyperglycemia impairs endothelial function and insulin sensitivity via different mechanisms in insulin-dependent diabetes mellitus. Circulation. 1996;94(6):1276-82.

18. Giacco F, Brownlee M. Oxidative stress and diabetic complications. Circ Res 2010;107(9):1058-70.

19. Wallace TW, Abdullah SM, Drazner MH, Das SR, Khera A, McGuire DK, et al. Prevalence and determinants of troponin T elevation in the general population. Circulation. 2006;113(16):1958-65.

20. Hallén J, Johansen OE, Birkeland KI, Gullestad L, Aakhuys S, Endresen K, et al. Determinants and prognostic implications of cardiac troponin T measured 
by a sensitive assay in type 2 diabetes mellitus. Cardiovasc Diabetol. 2010;9:52.

21. Everett BM, Cook NR, Magnone MC, Bobadilla M, Kim E, Rifai N, et al. Sensitive cardiac troponin T assay and the risk of incident cardiovascular disease in women with and without diabetes mellitus: the Women's Health Study. Circulation. 2011;123(24):2811-8.

22. Axelsson A, Ruwald MH, Dalsgaard M, Rossing K, Steffensen R, Iversen $K$. Serial measurements of high-sensitivity cardiac troponin $T$ after exercise stress test in stable coronary artery disease. Biomarkers. 2013;18(4):304-9.

23. Omland T, de Lemos JA, Sabatine MS, Christophi CA, Rice MM, Jablonski KA, et al. A sensitive cardiac troponin T assay in stable coronary artery disease. N Engl J Med. 2009;361(26):2538-47.

24. Omland T, Pfeffer MA, Solomon SD, de Lomos JA, RØsjØ H, Saltyté Benth J, et al. Prognostic value of cardiac troponin I measured with a highly sensitive assay in patients with stable coronary artery disease. J Am Coll Cardiol. 2013;61 (12):1240-9.

25. Giannitsis E, Spanuth E, Horsch A, Kleber ME, Koch W, Grammer TB, et al. High-sensitivity cardiac troponin $\mathrm{T}$ and $\mathrm{N}$-terminal pro-B-type natriuretic peptide predict mortality in stable coronary artery disease: results from the Ludwigshafen Risk and Cardiovascular Health (LURIC) study. Clin Chem Lab Med. 2013;51(10):2019-28.

26. Laufer EM, Mingels AM, Winkens MH, Joosen IA, Schellings MW, Leiner T, et al. The extent of coronary atherosclerosis is associated with increasing circulating levels of high sensitive cardiac troponin T. Arterioscler Thromb Vasc Biol. 2010;30(6):1269-75.

27. Apple FS. A new season for cardiac troponin assays: it's time to keep a scorecard. Clin Chem. 2009;55(7):1303-6.

28. Korosoglou G, Lehrke S, Mueller D, Hosch W, Kauczor HU, Humpert PM, et al. Determinants of troponin release in patients with stable coronary artery disease: insights from $\mathrm{CT}$ angiography characteristics of atherosclerotic plaque. Heart. 2011;97(10):823-31.

29. Yiu KH, Lau KK, Zhao CT, Chan YH, Chen Y, Zhen Z, et al. Predictive value of high-sensitivity troponin-l for future adverse cardiovascular outcome in stable patients with type 2 diabetes mellitus. Cardiovasc Diabetol. 2014;13:63.

30. Quadri G, D'ascenzo F, Bollati M, Moretti C, Sciuto F, Gonella A. Diffuse coronary disease: short- and long-term outcome after percutaneous coronary intervention. Acta Cardiol. 2013;68(2):151-60

31. Aronson D, Edelman ER. Revascularization for coronary artery disease in diabetes mellitus: Angioplasty, stents and coronary artery bypass grafting. Rev Endocr Metab Disord. 2010;11(1):75-86.

32. Thygesen K, Mair J, Katus H, Plebani M, Venge P, Collinson P, et al. Recommendations for the use of cardiac troponin measurement in acute cardiac care. Eur Heart J. 2010;31(18):2197-204.

33. Olivetti G, Abbi R, Quaini F, Kajstura J, Cheng W, Nitahara JA, et al. Apoptosis in the failing human heart. N Engl J Med. 1997;336(16):1131-41.

34. Kociol RD, Pang PS, Gheorghiade M, Fonarow GC, O'Connor CM, Felker GM. Troponin elevation in heart failure prevalence, mechanisms, and clinical implications. J Am Coll Cardiol. 2010;56(14):1071-8.

35. Castelli WP, Doyle JT, Gordon T, Hames CG, Hjortland MC, Hulley SB, et al. $\mathrm{HDL}$ cholesterol and other lipids in coronary heart disease. The cooperative lipoprotein phenotyping study. Circulation. 1977;55(5):767-72.

36. Ostrander Jr LD, Lamphiear DE, Carman WJ, Williams GW. Blood glucose and risk of coronary heart disease. Arteriosclerosis. 1981;1(1):33-7.

37. Stolar M. Glycemic control and complications in type 2 diabetes mellitus. Am J Med. 2010;123(3 Suppl):S3-11.

38. Bramlage P, Gitt AK, Schneider S, Deeg E, Tschöpe D. Clinical course and outcomes of type-2 diabetic patients after treatment intensification for insufficient glycaemic control - results of the 2 year prospective DiaRegis follow-up. BMC Cardiovasc Disord. 2014;14:162

39. Jousilahti P, Vartiainen E, Tuomilehto J, Puska P. Sex, age, cardiovascular risk factors, and coronary heart disease: a prospective follow-up study of 14786 middle-aged men and women in Finland. Circulation. 1999;99(9):1165-72.

\section{Submit your next manuscript to BioMed Central and take full advantage of:}

- Convenient online submission

- Thorough peer review

- No space constraints or color figure charges

- Immediate publication on acceptance

- Inclusion in PubMed, CAS, Scopus and Google Scholar

- Research which is freely available for redistribution 